\title{
Effects of Land Surface Temperature on the Frequency of Convective Precipitation in the Tokyo Area
}

\author{
Yohei Shiraki, Yoshinori Shigeta \\ Faculty of Geo-Environmental Science, Rissho University, Kumagaya, Japan \\ Email: shiraki@ris.ac.jp
}

Received March 7, 2013; revised April 12, 2013; accepted May 12, 2013

Copyright (C) 2013 Yohei Shiraki, Yoshinori Shigeta. This is an open access article distributed under the Creative Commons Attribution License, which permits unrestricted use, distribution, and reproduction in any medium, provided the original work is properly cited.

\begin{abstract}
This study uses statistical evaluation by correlation analysis to examine the effects of thermal environment on the frequency of convective precipitation in the Greater Tokyo Area between 12:00 and 18:00 on summer days from 1997 to 2006. To extract the frequency of convective precipitation we used Automated Meteorological Data Acquisition System radar data to obtain detailed rainfall distribution maps, and to extract the urban thermal environment we used surface temperature data from a National Oceanic and Atmospheric Administration weather satellite. Results were a coefficient of determination of 0.01, indicating no clear relation between surface temperature and convective rain frequency in the study area. Examining the convective rain frequency distribution map in conjunction with an elevation map of the area indicates that higher elevation is a better predictor of increased frequency of convective rainfall than is surface temperature. Because this indicates that orographic precipitation has a large influence in the study area, we used an elevation map to exclude hilly and mountainous regions, regions bordering flat areas (under the assumption that wind could easily move orographic precipitation to such areas), and regions containing marine areas. Doing so resulted in a coefficient of determination of 0.38 , a clear signal that differences in the thermal environment in the Greater Tokyo Area have an effect on the frequency of convective precipitation. We next focused on metropolitan Tokyo, the most developed part of the region and the part experiencing the most frequent occurrences of convective precipitation, and we performed correlation analysis considering parameters related to buildings. Results indicate that orographic precipitation has a strong influence in metropolitan Tokyo as well, so we excluded those areas that were excluded from the Greater Tokyo Area analysis and again performed correlation analysis. However, we found no clear relation of convective precipitation frequency with surface temperature or building parameters.
\end{abstract}

Keywords: Remote Sensing; Geographic Information System; Heat Island; Land Surface Temperature; Convective Precipitation

\section{Introduction}

Cities are spaces dedicated to human activity, and their unchecked growth has resulted in numerous problems. One such problem is the development of the urban heat islands (UHIs). The UHI effect is a phenomenon where the air temperature is higher in an urban environment than in the surrounding area, resulting in a direct impact on residents. There are also suggestions that the UHI effect influences mesoscale circulation in the city, potentially inducing convective precipitation.

There have been various discussions of the effects of factors other than differences in synoptic place occurring in urban environments, such as complex cityscapes [1-3] and urban aerosols [4-7]. An often-cited characteristic of such precipitation is increased precipitation amounts leeward of the city center [8-15]. There have also been reports of increased urban rainfall in Japan [16,17], and many reports indicating UHIs as a contributing factor [18-22].

Japanese megacities such as Tokyo already demonstrate the UHI effect, yet continue to expand to the point of assimilating smaller nearby towns. One serious consequence is that the increase in impervious surfaces can cause stormwater runoff to exceed wastewater treatment capacity, resulting in flooding. Convective precipitation in particular is difficult to predict and can result in heavy rainfall over a short time, so knowing what areas frequently experience convective precipitation and understanding the relationship between precipitation and UHIs is a first step in planning measures to address flood 
prevention and damage control measures.

The present study examines the urban and suburban areas of Tokyo (Figure 1), using statistical evaluation by correlation analysis to examine the effects of thermal environment on convective precipitation frequency. We also perform statistical analysis that focuses on the many convective precipitation events that occur in metropolitan Tokyo in the hope of finding a relation between differences in heat environment and event frequency. An example of convective precipitation in Tokyo is the 21 July 1999 event occurring at around 15:00, which brought rainfall of $129 \mathrm{~mm} / \mathrm{h}$.

From the definition of UHI, it is preferable to use temperature as the basis for evaluating differences in thermal environment. However, it is difficult to create a detailed temperature distribution map based on actual observations over an area as large as the one examined in this study, and ensuring observations under similar atmospheric conditions would be difficult and expensive. This study therefore uses satellite imaging to extract a surface temperature distribution, and for convenience, that distribution was used as the UHI in the study area.

As has been stated in previous studies, daytime surface temperatures obtained from satellites do not necessarily give an accurate depiction of UHIs [23], but satellite data have one significant advantage in that surface temperatures can be extracted for specified times and dates. The present study examines summer (July and August) surface temperatures in the daytime (12:00 to 18:00) from 1997 to 2006.

\section{Overview of Study Area}

Tokyo Metropolis contains the 23 wards that include the seat of the national government in Japan, and also covers
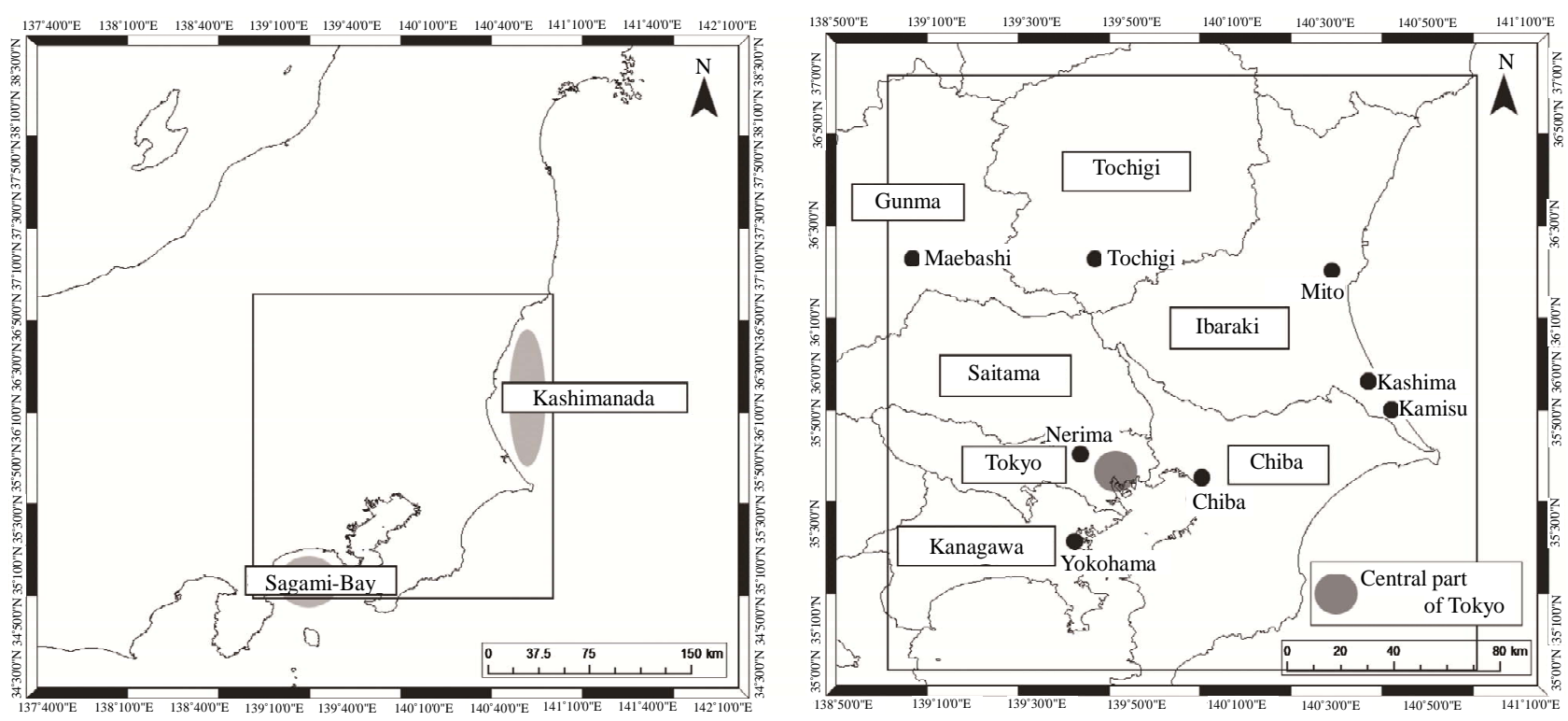

Figure 1. The study area. The square in the left panel encloses the study area. A magnified view is shown in the right panel. the Tama District, the Izu Islands, and the Ogasawara Islands. The Greater Tokyo Area, which covers the urban areas of Tokyo Metropolis and the surrounding prefectures of Kanagawa, Chiba, Saitama, Gunma, Tochigi, and Ibaraki, has a population of approximately 37 million people, making it the world's most populous metropolistan area [24].

With high concentrations of people, goods, money, and information, such large cities offer conveniences over smaller ones. However, such excessive concentrations can worsen urban environments. One example is the UHI effect, in which cities become warmer than do their surrounding areas; while the average temperature of Japan as a whole rose $1^{\circ} \mathrm{C}$ in the 20th century, Japan Meteorological Agency (JMA) data show that Tokyo's average temperature has risen approximately $3^{\circ} \mathrm{C}$.

Approximately $70 \%$ of the world's population is expected to live in urban regions by 2050 [25], and environmental problems similar to those of existing cities are expected to arise in newly developing cities as well. Using Tokyo as a case study of evident indirect problems such as increased levels of convective rain due to a worsened thermal environment can therefore provide vital data for consideration when developing cities planning measures against similar problems.

\section{Data and Analysis}

\subsection{Frequency of Convective Precipitation}

We used data from the Automated Meteorological Data Acquisition System (AMeDAS) to extract information for measuring the frequency of convective precipitation. AMeDAS consists of radar stations operated by JMA and the River Bureau and the Road Bureau of the Ministry of 
Land, Infrastructure, and Transport, as well as approximately 1300 automated weather stations. This system collects data from ground-level rain gauges, which can be used to collect detailed information about rainfall.

AMeDAS rainfall data from 1988 through March 2001 used a mesh with $5 \mathrm{~km}$ resolution, but that was increased to $2.5 \mathrm{~km}$ resolution in April 2001, and again to $1 \mathrm{~km}$ in January 2006. For consistency, this paper uses data over a $5 \mathrm{~km} \times 5 \mathrm{~km}$ mesh. Note also that starting in May 2003 the coordinate system was changed from Japan datums to geodetic datums, but this study uses geodetic datums throughout for consistency. The time resolution of the data is $1 \mathrm{~h}$.

Because the present study aims at extracting those convection precipitation events considered to be the result of factors related to the UHI effect, it is necessary, to the extent possible, to remove from consideration effects that are due to differences in synoptic place. We therefore omitted data for days of weather phenomena such as fronts, low pressure systems, and typhoons, and used the following four criteria for classifying a day as one experiencing convective precipitation.

- There was a gradual change in pressure gradient from the Sea of Japan (Niigata City) to the Pacific Ocean (Tokyo), and there was good sea breeze circulation.

- No precipitation systems had moved over land from the sea.

- Total rainfall was less than $0.5 \mathrm{~mm} / \mathrm{h}$ at the Tokyo District Meteorological Observatory.

- There was on average $50 \mathrm{~min} / \mathrm{h}$ sunlight from sunrise until 12:00 at the Tokyo District Meteorological Observatory.

The convective rain rate was calculated as the total number of times that rainfall began within $1 \mathrm{~h}$ during the observation period for days meeting the above conditions.

\subsection{Calculation of Surface Temperature}

To extract surface temperatures, we visually selected photographs featuring low cloud cover which were acquired by the Advanced Very High Resolution Radiometer (AVHRR) sensors on the National Oceanic and Atmospheric Administration (NOAA) 12 and 14 satellites to create composite images. Spatial resolution of the AVHRR sensors is $1.1 \mathrm{~km}$ from orbit. We used the split window method (Equation (1) [26]) to calculate surface temperatures from the difference in brightness temperature between AVHRR Channels 4 and 5:

$$
T(K)=C h .4+3.33(\text { Ch.4 }- \text { Ch.5 })
$$

The above method gives the temperature in kelvins, so values were converted to degrees Celsius before use in analysis.

\section{Results and Discussion}

\subsection{Convective Precipitation and Surface Temperature Distributions}

Figure 2 shows the distribution of convective precipitation frequency in the study area, and indicates that frequency increases in a WNW direction from the city center. This is similar to previously reported phenomena [27, 28], a pattern in which easterly wind from the Kashimanada coast and southerly wind from the Sagami Bay coast converge in the Tokyo area.

There is also a tendency for more frequent convective precipitation in Chiba Prefecture, to the north and west of the study area. Comparison with a topographic map created with Advanced Spaceborne Thermal Emission and Reflection Radiometer (ASTER) Global Digital Elevation Model (GDEM) shows that these areas have relatively high altitude (Figure 3), suggesting that rainfall in these areas is not convective precipitation due to an urban thermal environment, but rather orographic precipitation due to geographically induced updrafts.

Figure 4 shows a distribution of surface temperatures in the study area. While NOAA/AVHRR data are from directly below orbit and provided at a $1.1 \mathrm{~km}$ resolution, we used a $5 \mathrm{~km} \times 5 \mathrm{~km}$ mesh of averaged values to allow correlation analysis. Results show a tendency for central city areas from Yokohama to Chiba City to have significantly higher temperatures, which decrease toward the suburbs. Higher temperatures are also seen in prefectural capitals such as Maebashi, Tochigi, and Mito, and in the cities of Kamisu and Kashima, site of the Kashima Coastal Industrial Zone, the largest industrial agglomeration in Ibaraki Prefecture. Comparing these areas with the elevations in Figure 3, areas at higher elevations have relatively low surface temperatures.

\subsection{Relation between Convective Precipitation and Surface Temperature}

Figure 5 shows the relation between convective precipitation frequency and surface temperature. The colored bars in that figure indicate average values in the $5 \mathrm{~km} \times 5$ $\mathrm{km}$ mesh. The coefficient of correlation for this relation is 0.01 , indicating no positive relation between the frequency of convective precipitation and surface temperature. In other words, no increased frequency of convective rain is indicated as a result of higher surface temperature.

As described above, however, we observed a significant influence of orographic features on convective rainfall frequency in the study area. We therefore performed the analysis again after removing mesh areas containing mountainous or hilly geography. We also removed 


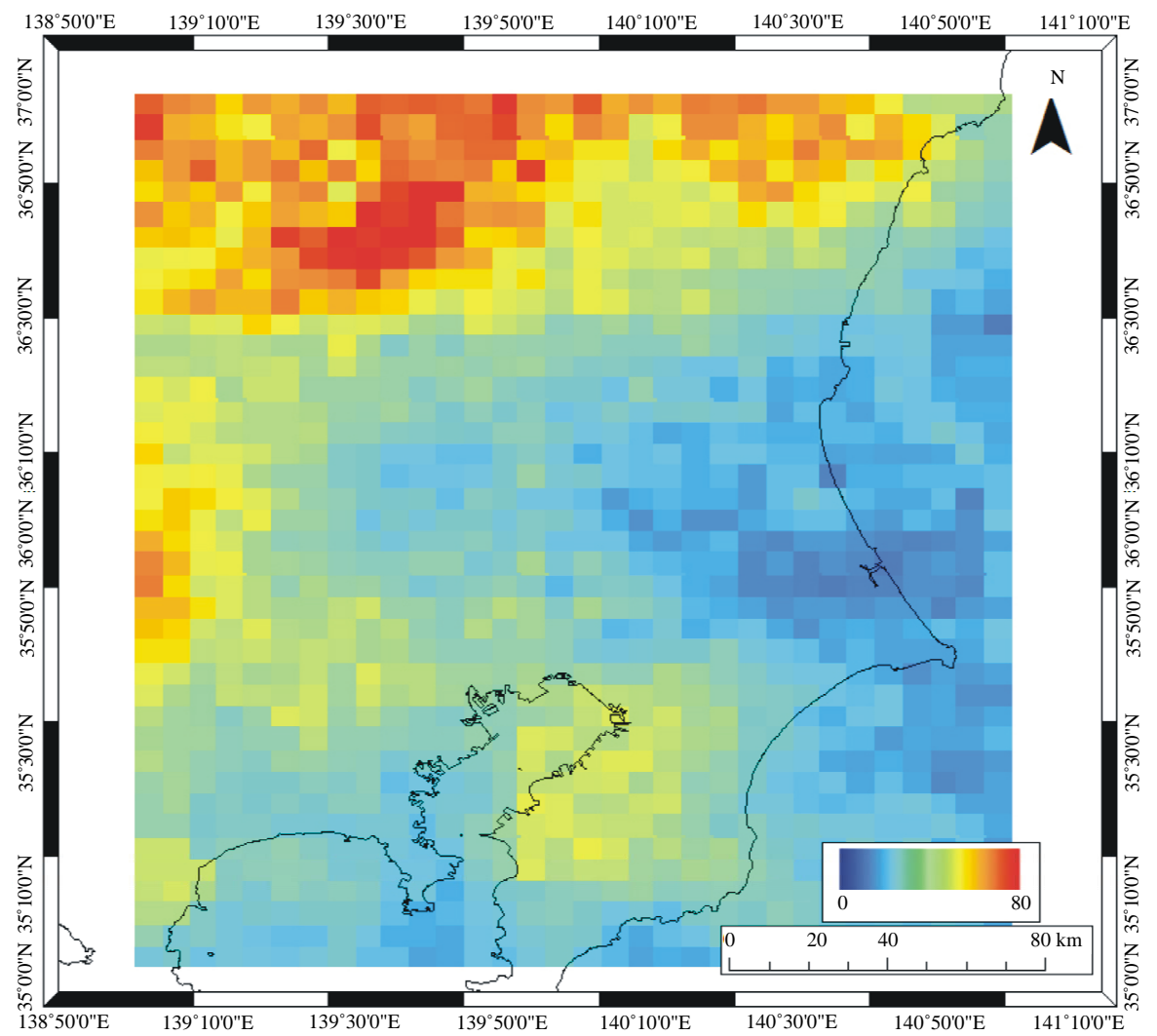

Figure 2. Convective precipitation frequency distribution from AMeDAS radar analysis.

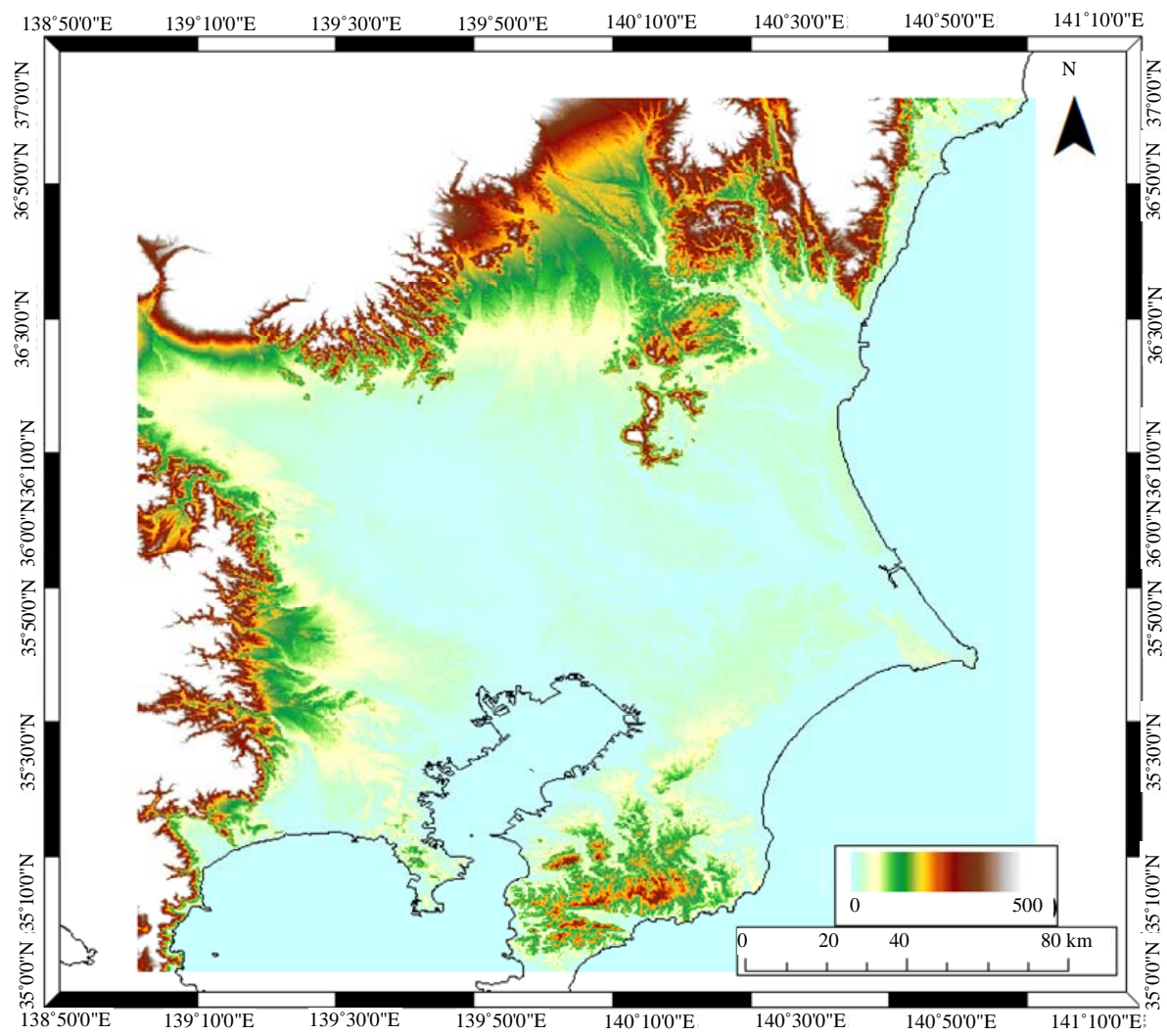

Figure 3. Topographic map of the study area, prepared using ASTER GDEM. 


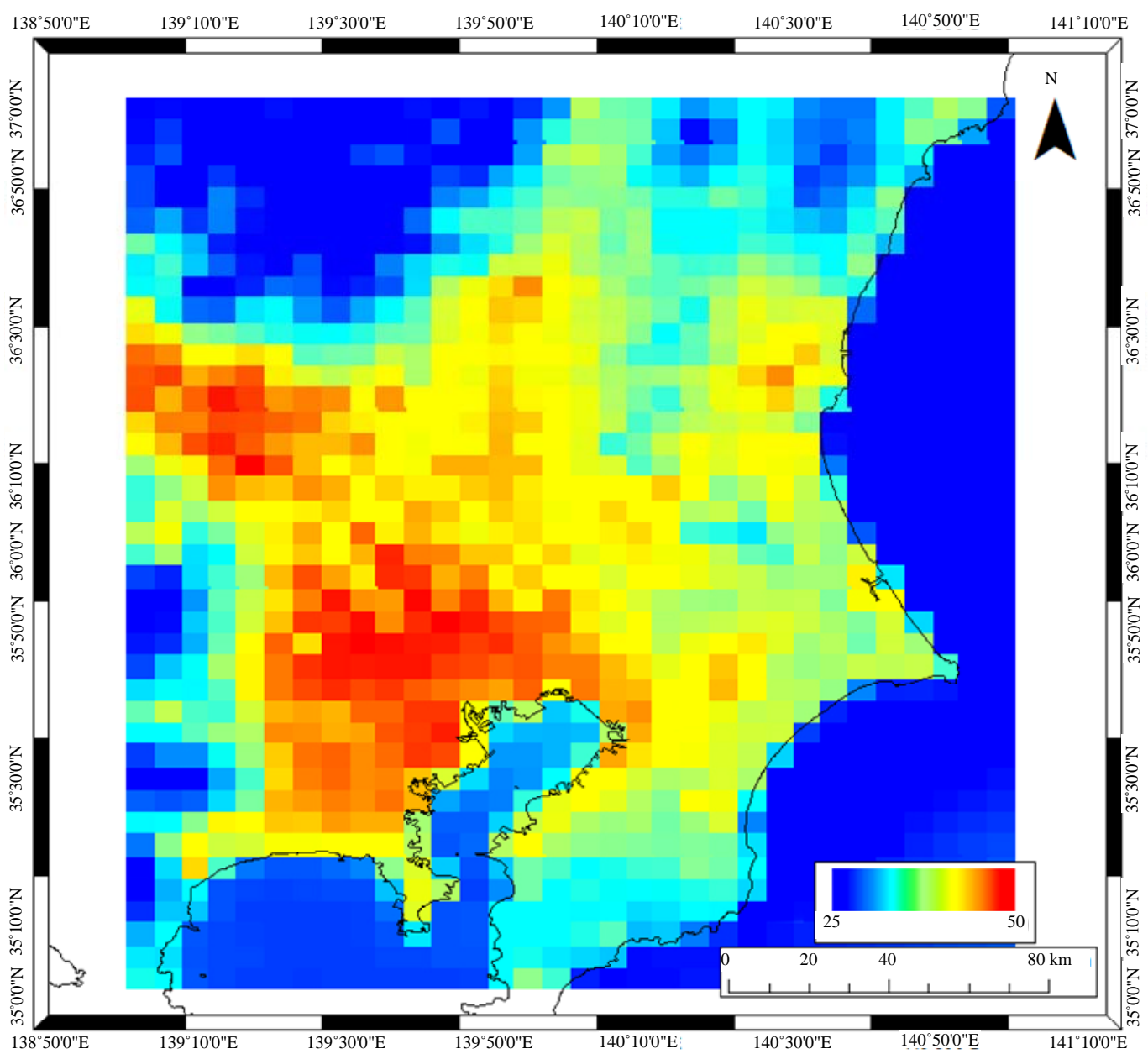

Figure 4. Surface temperatures from NOAA/AVHRR data. This distribution uses a $5 \mathbf{~ k m} \times 5 \mathbf{~ k m ~ m e s h ~ s i m i l a r ~ t o ~ t h a t ~ u s e d ~ f o r ~}$ the convective precipitation frequency distribution, created from averaged values.

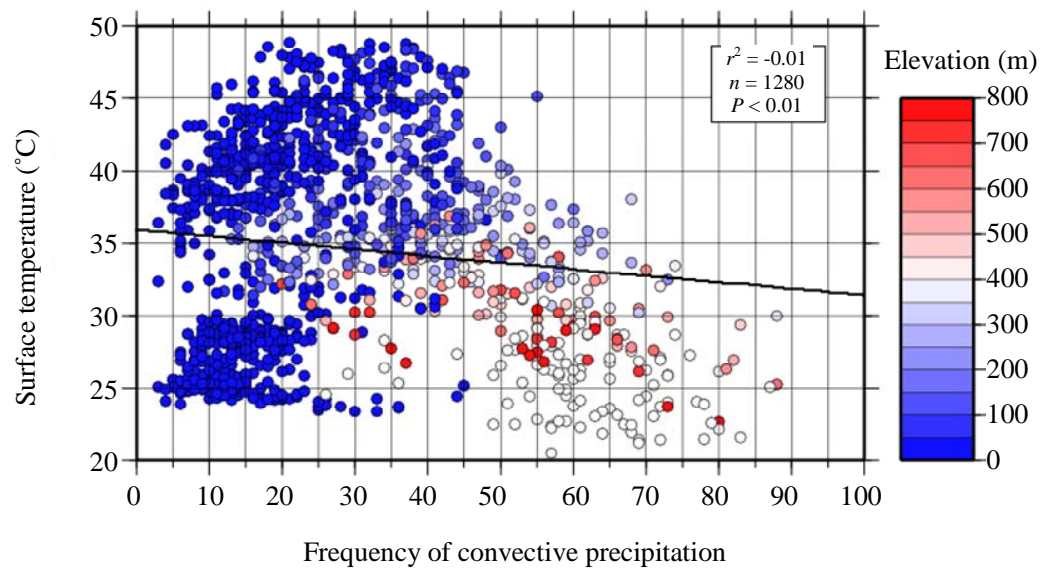

Figure 5. Relation between convective precipitation frequency and surface temperature.

meshes lying between mountainous or hilly areas and plains, on the assumption that wind would easily carry precipitation caused by geographic features. Finally, because marine areas likely contain information not helpful in evaluations of urban thermal environments, we also removed meshes containing marine areas (Figure 6). The resulting coefficient of correlation was 0.38 (Figure 7), an indication that differences in thermal environment have an effect on the frequency of convective precipitation in the study area. 


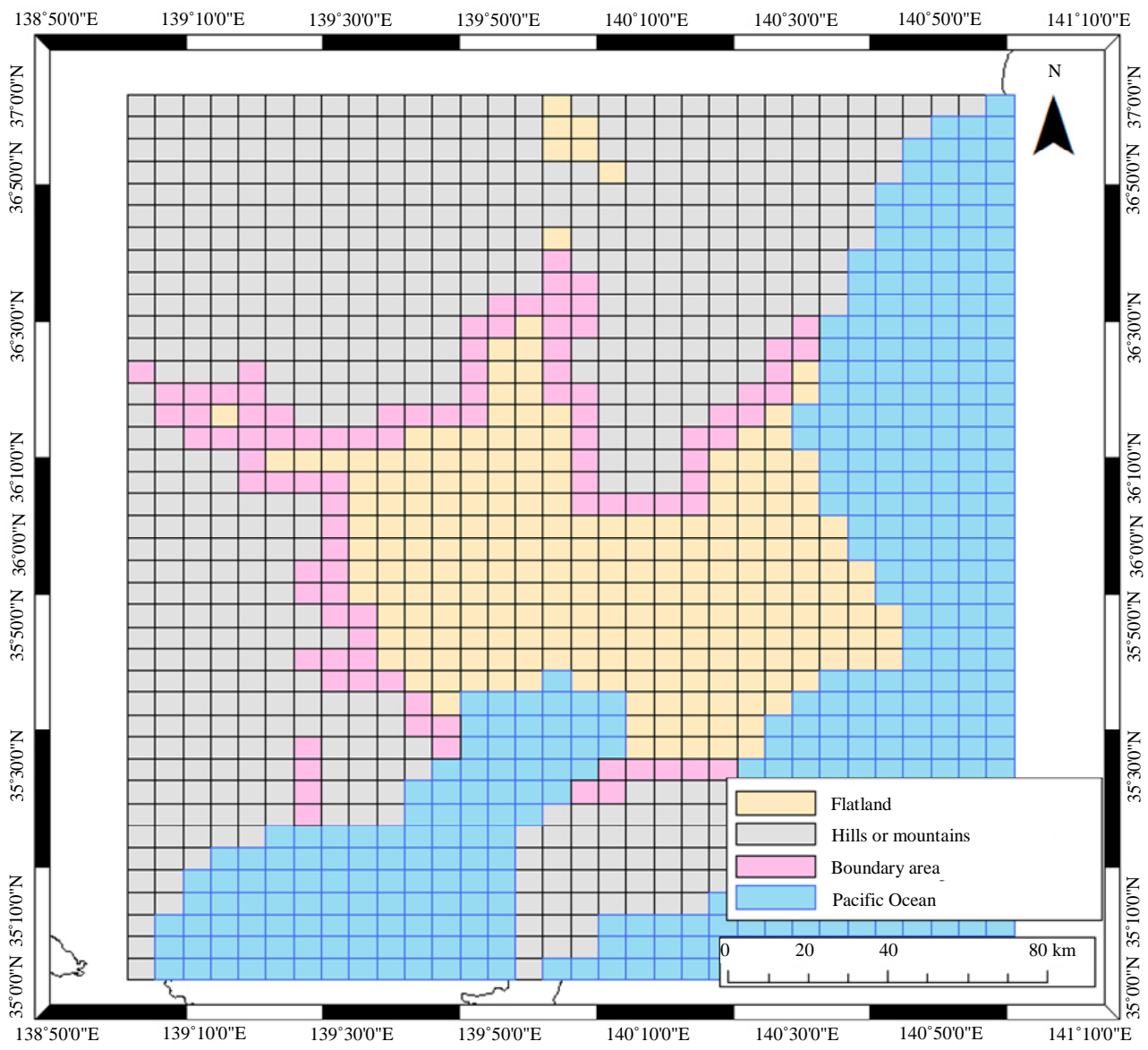

Figure 6. The $5 \mathrm{~km} \times 5 \mathrm{~km}$ mesh, showing those regions containing mountainous, hilly, border, and marine areas.

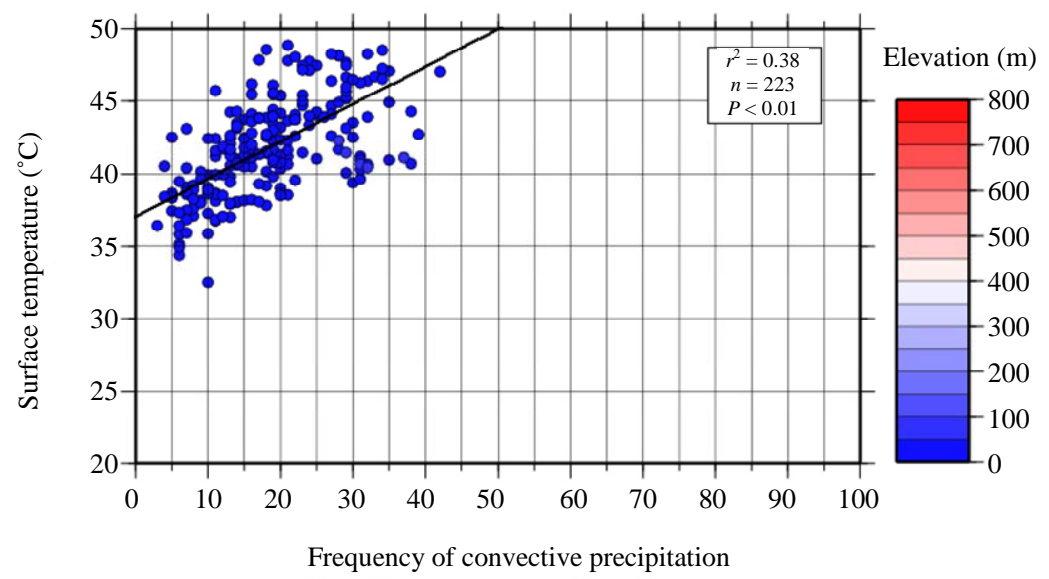

Figure 7. Relation between convective precipitation frequency and surface temperature. This is the mesh from Figure 5, excluding mountainous, hilly, border, and marine areas.

\subsection{Relations of Convective Precipitation with Surface Temperature and Building Parameters}

As exemplified by its massive population and the complexity of its skyline, metropolitan Tokyo in particular is a notable example of a developed area, as well as an area of frequent convective precipitation. An evaluation of the effect of thermal environment on convective precipitation frequency in Tokyo is therefore likely to provide vital information when planning for measures to keep eventual damage from convective precipitation to a minimum.

As described above, however, megacities like Tokyo 
experience not only the UHI effect, but also the effect of a complex cityscape that alters the mesoscale circulation of winds through the city in ways that can trigger precipitation. In addition to ground temperature, therefore, we extended our statistical evaluation to correlation analysis of building parameters as factors affecting convective precipitation in Tokyo. When doing so, we used the same data for convective precipitation frequency and ground temperature as were used in the previous section.

There have been numerous previous studies on the effect of the roughness length $\mathrm{z} 0$ building parameter, but because roughness length varies with wind direction, it is difficult to incorporate into this study, which is a composite of multiple days. We therefore used the building density, average number of floors, and standard deviation of number of floors in each $5 \mathrm{~km} \times 5 \mathrm{~km}$ grid as building parameters.

We used Tokyo Urban Planning GIS data from 1996 and 1997 to calculate building parameter values (Figure 8). Figure 9 shows the relations of convective precipitation frequency with surface temperature and building parameters. The color bar in the figure shows average elevations within the $5 \mathrm{~km} \times 5 \mathrm{~km}$ mesh. Results indicate an increase in convective precipitation with increased elevation for each factor, but no positive correlation is seen between any variable pair. In other words, no relation is indicated in which the frequency of convective precipitation increases with increased surface temperature, building density, average number of building floors, or standard deviation of number of building floors.

This indicates that orographic factors have a strong effect on rainfall in metropolitan Tokyo, too. We therefore applied the same exclusion conditions to metropolistan Tokyo that we did for the Greater Tokyo Area analysis, excluding mountainous and hilly terrain, a one-mesh border along such regions, and seaside regions. As Figure 10 shows, the results again did not indicate a clear relation of convective precipitation frequency with surface temperature or building parameters.

This indicates that it is difficult to extract a signal using only surface temperatures and building parameters in Tokyo, even when orographic effects are removed. This

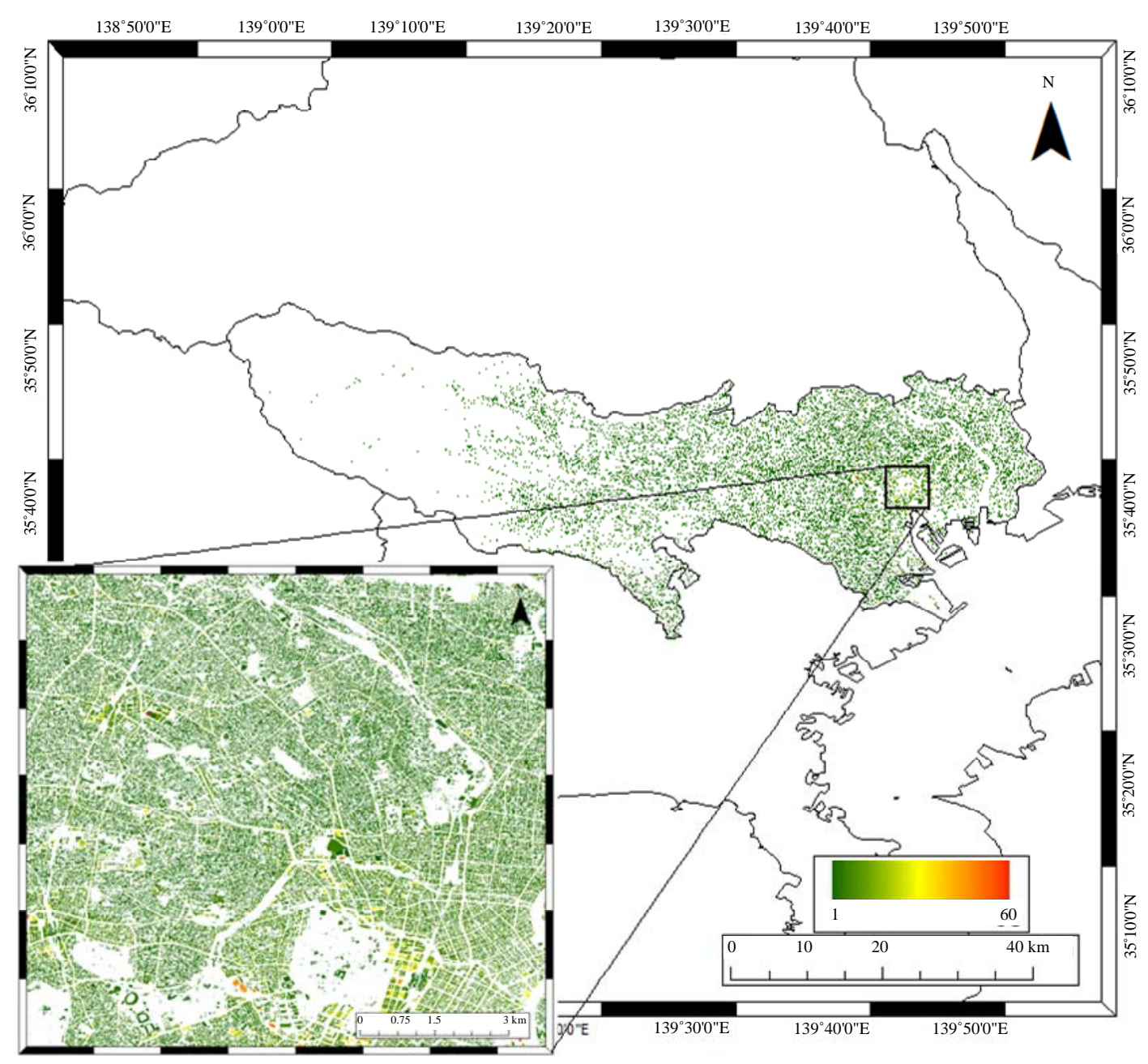

Figure 8. Building usage from Tokyo Urban Planning GIS data. Colored bars indicate the number of building stories. 

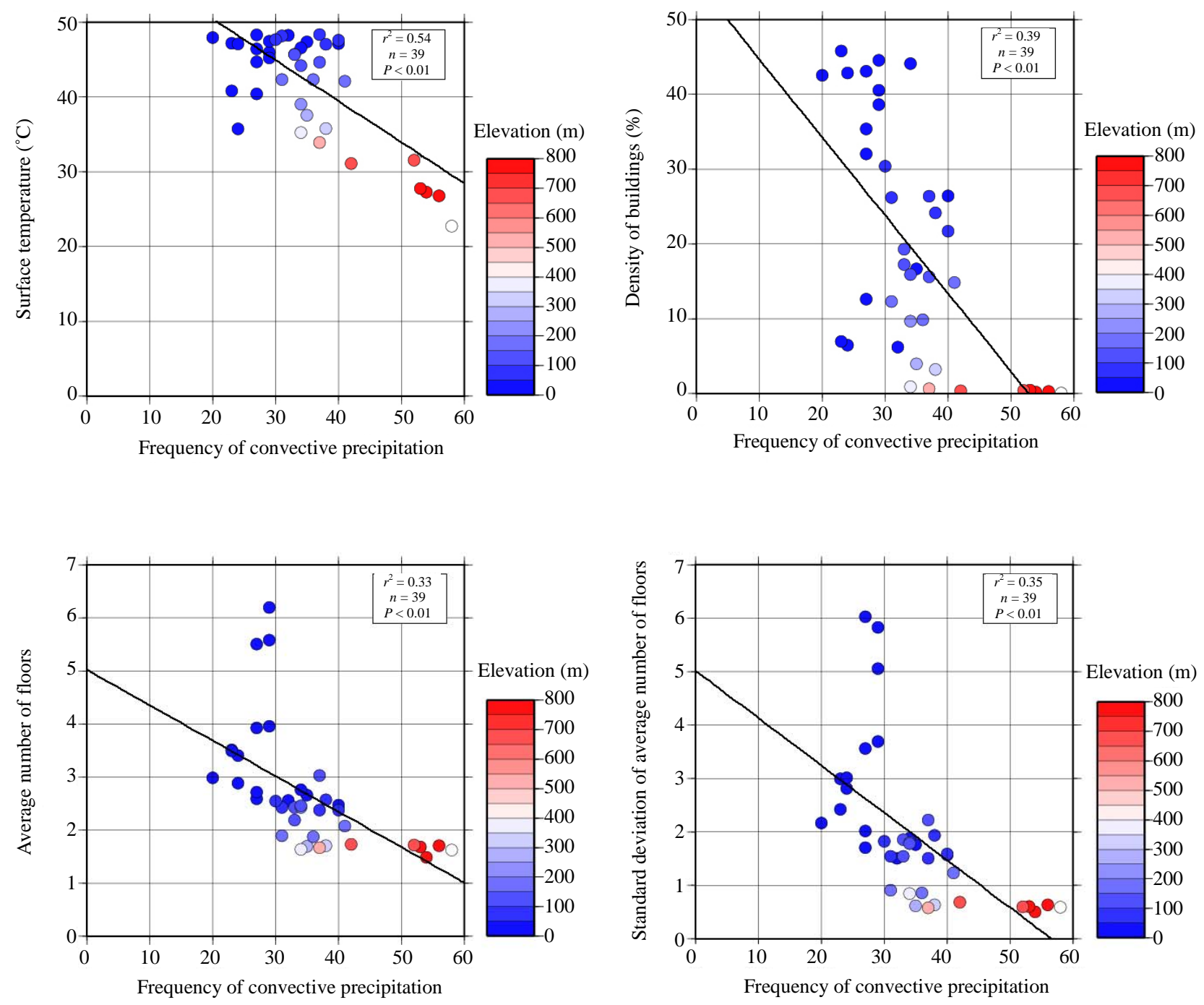

Figure 9. The relation between convective precipitation frequency and surface temperature (upper left), building density (upper right), average number of stories (lower left), and standard deviation of number of stories (lower right) in a $5 \mathrm{~km} \times 5$ km mesh.

might be because in a megacity like Tokyo there exists a complicated set of other factors affecting convective precipitation, such as aerosols that promote cloud formation and layered wind formations.

\section{Conclusions}

To investigate whether UHIs affect mesoscale circulation in urban areas and thus contribute to convective precipitation, we performed statistical evaluation by correlation analysis to examine the effect of thermal environment on the frequency of convective precipitation in the Greater Tokyo Area. We also focused on metropolitan Tokyo, the most developed region within the study area, and again evaluated relations between convective precipitation frequency and building parameters in addition to ground temperature. We used rainfall amounts from
AMeDAS radar to extract convective precipitation frequency data, data from NOAA/AVHRR for calculations of the thermal environment, and Tokyo Urban Planning GIS data from 1996 and 1997 to calculate building parameters. Results were as follows:

- We verified a previously reported tendency for increased convective precipitation frequency WNW from the city center. We also found increased convective precipitation frequency in Chiba Prefecture to the north and west of the study area, but we attribute this to orographic factors, not urban thermal environment.

- The surface temperature distribution in the study area shows a marked temperature increase around central Tokyo, from Yokohama to Chiba City. Temperatures fall as one moves toward the suburbs. Temperatures are also relatively higher in prefectural capitals and around industrial zones, and decrease with elevation. 

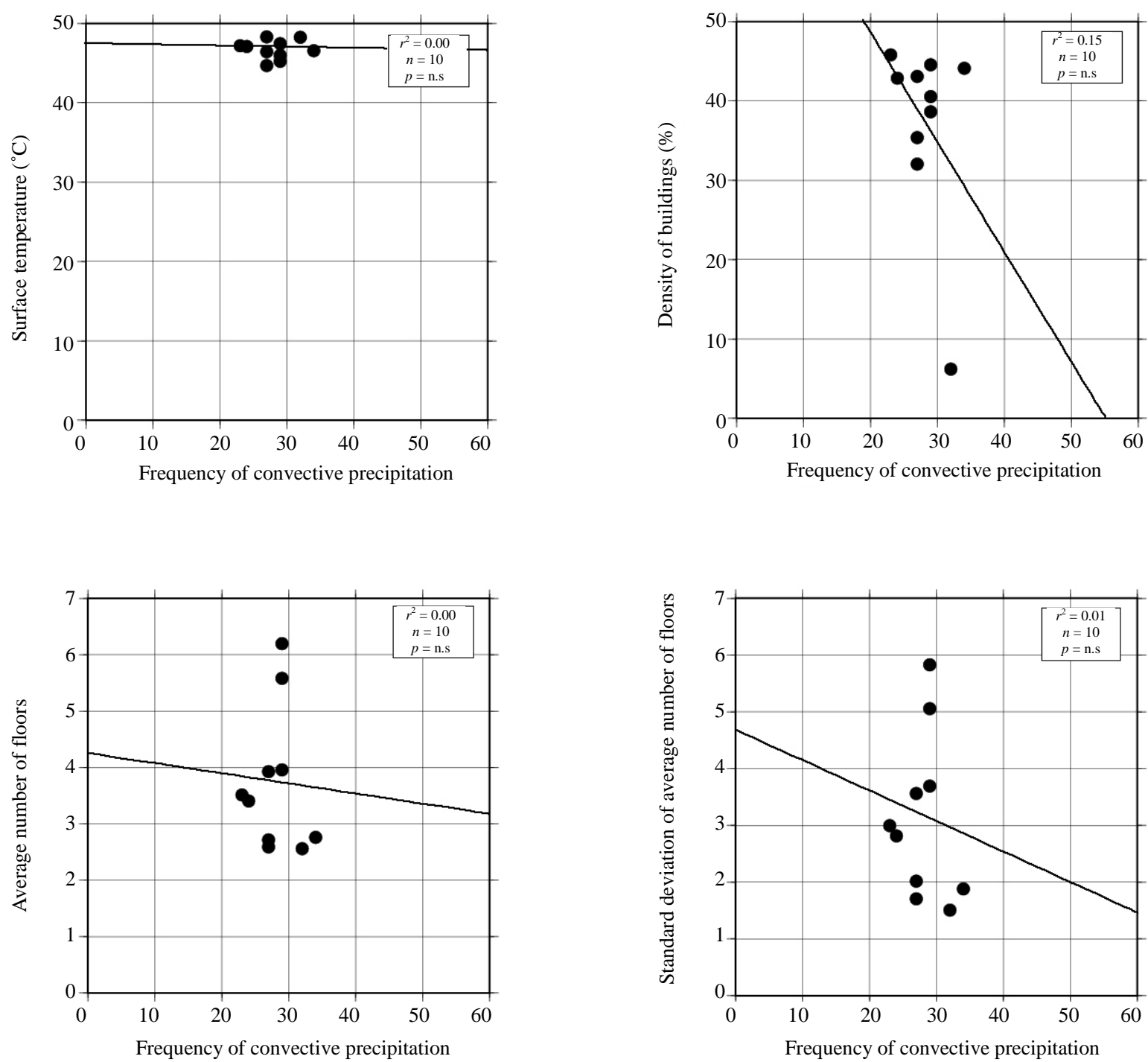

Figure 10. Relations of convective precipitation frequency with surface temperature (upper left), building density (upper right), average number of stories (lower left), and standard deviation of number of stories (lower right) in a $5 \mathrm{~km} \times 5 \mathrm{~km}$ mesh. The mesh used here excludes mountainous, hilly, borderline, and marine areas, as in the analysis of the Greater Tokyo Area.

- Statistical analysis of the study area as a whole for the relation between frequency of convective precipitation and surface temperature results in a coefficient of correlation of 0.01 , but excluding mountainous, hilly, borderline, and marine regions from the analysis mesh gives a coefficient of correlation of 0.38 , a clear signal that urban thermal environments affect the frequency of convective precipitation.

We also evaluated the relations of convective precipitation frequency with surface temperature and building parameters in central Tokyo, the region in the study area with the most extensive urban development and the highest frequency of convective precipitation. Results indicated that geography is a major influence there as well, and no clear correlation was indicated between the various factors. We also attempted to exclude geographic effects by re-performing the analysis after removing meshes similar to those described in 3) above, but still found no positive correlation. We believe this is an indicator that in megacities such as Tokyo there are multiple factors besides surface temperature and building parameters that affect the frequency and location of convective precipitation, and that these factors exist in a complex interrelation.

From the above, we conclude that while it is possible to extract signals related to the influence of differences in thermal environment in broad study areas such as the Greater Tokyo Area, when the study area is narrowed the differences between urban and suburban regions become less clear. Furthermore, because there are complex mul- 
tiple factors affecting the frequency and location of convective precipitation in cityscapes, fully understanding this phenomenon will require a more complex analysis that considers these additional factors. It is therefore important that future research investigates other factors related to convective precipitation, and creates distribution maps with a higher spatial resolution than those used in this study. This study used statistical methods to analyze the relation between surface temperature and convective precipitation frequency, but future research should consider not only statistical significance, but also consistency with previous research and known physical properties.

\section{Acknowledgements}

This research was supported by a JSPS Grant-in-Aid for Scientific Research 22700859.

\section{REFERENCES}

[1] M. R. Hjelmfelt, "Numerical Simulation of the Effects of St. Louis on Mesoscale Boundary-Layer Airflow and Vertical Motion: Simulations of Urban vs Non-Urban Effects," Journal of Applied Meteorology, Vol. 21, No. 9, 1982, pp. 1239-1257. doi:10.1175/1520-0450(1982)021<1239:NSOTEO>2.0.C $\underline{\mathrm{O} ; 2}$

[2] R. Bornstein and Q. Lin, "Urban Heat Islands and Summertime Convective Thunderstorms in Atlanta: Three Cases Studies," Atmospheric Environment, Vol. 34, No. 3, 2000, pp. 507-516. doi:10.1016/S1352-2310(99)00374-X

[3] C. M. Rozoff, W. R. Cotton and J. O. Adegoke, "Simulation of St. Louis, Missouri, Land Use Impacts on Thunderstorms," Journal of Applied Meteorology, Vol. 42, No. 6, 2003, pp. 716-738.

doi:10.1175/1520-0450(2003)042<0716:SOSLML >2.0.C $\underline{\mathrm{O} ; 2}$

[4] M. Jin, J. M. Shepherd and M. D. King, "Urban Aerosols and Their Variations with Clouds and Rainfall: A Case Study for New York and Houston," Journal of Geophysical Research, Vol. 110, No. D10, 2005, Article ID: D10S20. doi:10.1029/2004JD005081

[5] S. C. van den Heever and W. R. Cotton, "Urban Aerosol Impacts on Downwind Convective Storms," Journal of Applied Meteorology and Climatology, Vol. 46, No. 6, 2007, pp. 828-850. doi:10.1175/JAM2492.1

[6] T. L. Bell, D. Rosenfeld, K.-M. Kim, J.-M. Yoo, M.-I. Lee and M. Hahnenberger, "Midweek Increase in US Summer Rain and Storm Heights Suggests Air Pollution Invigorates Rainstorms," Journal of Geophysical Research, Vol. 113, No. D2, 2008. Article ID: D02209. doi:10.1029/2007JD008623

[7] J-Y. Han, J-J. Baik and A. P. Khain, “A Numerical Study of Urban Aerosol Impacts on Clouds and Precipitation,” Journal of the Atmospheric Sciences, Vol. 69, No. 2, 2012, pp. 504-520. doi:10.1175/JAS-D-11-071.1

[8] H. E. Landsberg, “Man-Made Climate Changes: Man’s
Activities Have Altered the Climate of Urbanized Areas and May Affect Global Climate in the Future," Science, Vol. 170, No. 3964, 1970, pp. 1265-1274. doi:10.1126/science.170.3964.1265

[9] S. A. Changnon, "Rainfall Changes in Summer Caused by St. Louis,” Science, Vol. 205, No. 4404, 1979, pp. 402-404. doi:10.1126/science.205.4404.402

[10] S. A. Changnon and F. A. Huff, "The Urban RelatedNocturnal Rainfall Anomaly at St. Louis,” Journal of Climate and Applied Meteorology, Vol. 25, No. 12, 1986, pp. 1985-1995.

doi:10.1175/1520-0450(1986)025<1985:TURNRA>2.0.C $\underline{\mathrm{O} ; 2}$

[11] E. Jauregui and E. Romales, "Urban Effects on Convective Precipitation in Mexico City," Atmospheric Environment, Vol. 30, No. 20, 1996, pp. 3383-3389. doi:10.1016/1352-2310(96)00041-6

[12] J. M. Shepherd, H. Pierce and A. J. Negri, "Rainfall Modification by Major Urban Areas: Observations from Spaceborne Rain Radar on the TRMM Satellite,” Journal of Applied Meteorology, Vol. 41, No. 7, 2002, pp. 689701.

doi:10.1175/1520-0450(2002)041<0689:RMBMUA>2.0. $\mathrm{CO} ; 2$

[13] P. G. Dixon and T. L. Mote, "Patterns and Causes of Atlanta's Urban Heat Island-Initiated Precipitation,” Journal of Applied Meteorology, Vol. 42, No. 9, 2003, pp. 12731284. doi:10.1175/1520-0450(2003)042<1273:PACOAU >2.0.C $\mathrm{O} ; 2$

[14] T. L. Mote, M. C. Lacke and J. M. Shepherd, "Radar Signatures of the Urban Effect on Precipitation Distribution: A Case Study for Atlanta, Georgia,” Geophysical Research Letters, Vol. 34, No. 20, 2007, Article ID: L20710. doi:10.1029/2007GL031903

[15] L. S. Rose, J. A. Stallins and M. L. Bentley, "Concurrent Cloud-to-Ground Lightning and Precipitation Enhancement in the Atlanta, Georgia (United States), Urban Region," Earth Interactions, Vol. 12, No. 11, 2008, pp. 130. doi:10.1175/2008EI265.1

[16] M. Yoshino, "Climate Change in the Urban Area in Japan and the Foreign Countries," Meteorological Research Note, No. 133, 1977, pp. 1-25. (in Japanese)

[17] T. Yonetani, "Increase in Number of Days with Heavy Precipitation in Tokyo Urban Area," Journal of Applied Meteorology, Vol. 21, No. 10, 1982, pp. 1466-1471. doi:10.1175/1520-0450(1982)021<1466:IINODW>2.0.C $\underline{\mathrm{O} ; 2}$

[18] T. Yonetani, "Enhancement and Initiation of a Cumulus by a Heat Island,” Journal of the Meteorological Society of Japan, Vol. 61, No. 2, 1983, pp. 244-253. (in Japanese)

[19] T. Yonetani, "Study of the Urban Effects on the Occurrence of Convective Precipitation,” Report of the National Research Center for Disaster Prevention, No. 44, 1989, pp. 1-59.

[20] F. Fujibe, "Spatial Anomalies and Long-Term Changes of Precipitation in Tokyo,” Tenki, Vol. 45, No. 1, 1998, pp. 7-18. (in Japanese) 
[21] N. Sato and M. Takahashi, "Long-Term Changes in the Properties of Summer Precipitation in the Tokyo Area," Tenki, Vol. 47, No. 9, 2000, pp. 643-648. (in Japanese)

[22] T. Sato, T. Terashima, T. Inoue and F. Kimura, "Intensification of Convective Precipitation Systems over Tokyo Urban Area in Summer Season,” Tenki, Vol. 53, No. 6, 2006, pp. 479-484. (in Japanese)

[23] M. Roth, T. R. Oke and W. J. Emery, "Satellite-Derived Urban Heat Islands from Three Coastal Cities and the Utilization of Such Data in Urban Climatology,” International Journal of Remote Sensing, Vol. 10, No. 11, 1989, pp. 1699-1720. doi:10.1080/01431168908904002

[24] Demographia, "Demographia World Urban Areas," 8th Edition, 2013. http://esa.un.org/unup/pdf/WUP2011_Highlights.pdf

[25] United Nations, "World Urbanization Prospects. The 2011 Revision,” 2013.
http://esa.un.org/unup/pdf/WUP2011_Highlights.pdf

[26] C. J. Price, "Land Surface Temperature Measurement from the Split Window Channels of the NOAA 7 Advanced Very High Resolution Radiometer" Journal of Geophysical Research, Vol. 89, No. D5, 1984, pp. 72317237. doi:10.1029/JD089iD05p07231

[27] F. Fujibe, K. Sakagami, K. Chubachi and K. Yamashita, "Surface Wind Patterns Preceding Short-time Heavy Rainfall in Tokyo in the Afternoon of Midsummer Days," Tenki, Vol. 49, No. 5, 2002, pp. 395-405. (in Japanese)

[28] T. Mikami, H. Yamamoto, H. Ando, H. Yokoyama, T. Yamaguchi, M. Ichino, Y. Akiyama and K. Ishii, "Climatological Study on the Summer Intensive Heavy Rainfall in Tokyo,” Annual Report of the Tokyo Metropolitan Research Institute for Environmental Protection, 2005, pp. 33-42. (in Japanese) 